\title{
Effects of Climate Change and Human Activity on Runoff in a Typical Loess Gullied-Hilly Region Watershed
}

\author{
Xizhi Lv, Zhongguo Zuo, Peiqing Xiao*, Yongxin Ni, Juan Sun \\ Yellow River Institute of Hydraulic Research, Key Laboratory of the Loess Plateau Soil Erosion \\ and Water Loss Process and Control of Ministry of Water Resources, Zhengzhou, Henan 450003, China
}

Received: 31 May 2017

Accepted: 27 July 2017

\begin{abstract}
Human activity and climate are two main factors directly influencing catchment runoff, and separation of their impacts is of great importance for land use planning and water resource management. This study was designed to examine the impacts of climate change and human activity on stream flow characteristics. Using the nonparametric Mann-Kendall test and moving t-test, we accessed the trends and change points of the runoff, precipitation, and potential evapotranspiration data series in the watershed. And Zhang's function was employed to evaluate the impacts of variation in climate and human activity on mean annual stream flow. The results showed a significant downtrend and change points in annual runoff, with an abrupt change identified in 2001 in the whole watershed, and the stream flow data was divided into a baseline period and a period of change. The decrease in mean annual runoff between the baseline and the period of change indicated that climate change accounted for about $33.1 \%$ of the total decrease, and that human activity was responsible for about $66.9 \%$. This study concluded that human activity will significantly impact water resources in the Loess Plateau region, and scientific management measures should be implemented in the future.
\end{abstract}

Keywords: runoff, climate change, human activity, abrupt change, Loess Plateau

\section{Introduction}

Fluvial runoff is intensively affected by the integrative action of natural factors such as climate, relief, soil, vegetation, and human activity, exhibiting some evolution process but simultaneously presenting obvious randomness [1]. The very high spatial and temporal variability of fluvial processes in the region or watershed

*e-mail: nihulvxizhi@163.com also creates problems for measuring, monitoring, and assessing effects.

Climate change has resulted in the rise of atmospheric temperature and a modified pattern of precipitation and evapotranspiration, which has directly led to alteration of the regional hydrological cycle [2-3]. The abrupt change in total precipitation and a bias toward more intense rainfall events are of great concern in the assessment of potential impacts on soil erosion, water resources, and ecosystems, because most soil loss and environmental damage is caused by infrequent severe storms [4-5]. The potential for such projected climate changes to increase the risk of soil 
erosion and related environmental consequences is clear, but the potential damage in particular regions needs to be assessed [6]. In addition to socio-economic and climatic changes, DeFries and Eshleman expect land use change to have a strong impact on the water balance of river catchments. Human-induced land use change can affect water circulation and the spatial-temporal variations in the distribution of water circulation and the spatialtemporal variations in the distribution of water resources [7]. A number of studies have shown that changes in vegetation cover, i.e., afforestation or deforestation, lead to a reduction or increase in water yield, and such changes have been observed in catchments of different areas ranging from less than $1 \mathrm{~km}^{2}$ to more than $1,000 \mathrm{~km}^{2}$ [8]. Besides this, to satisfy the water demand of industrial and agricultural development, irrigation, and drainage, for example, will all greatly change hydrological cycles both over time and space.

In order to assess the impacts of climate change and land use change on hydrological cycles, many studies have been conducted based on traditional statistical methods and hydrological models [9]. However, traditional statistical methods lack a physical basis and reduce computational accuracy. Modeling of regional water fluxes and water balances requires different spatial data sets representing the landscape structure and catchment properties. Typically, information on topography, soils, and vegetation is needed if process-based models are applied. So, the major obstacles for hydrological models require a considerable amount of information which, in many cases, may not be available. Due to these limitations, a method that has a solid scientific base and is of great practical use and is highly desirable. The framework proposed by Milly and Dunne to describe the first-order effect of changes in precipitation and potential evaporation on runoff based on the Budyko Hypothesis has drawn wide attention [10]. It can be used to study hydrological response to changes in climate and hence enable separation of the effect of climate change on runoff from that of human activity [11]. A key problem of the method is the calculation of mean annual evaporation, for which the Budyko Hypothesis and similar functions have provided a reasonable and convenient solution.

The Loess Plateau is an area with heavy soil and water loss. Since the latter half of the 20th Century, the region has been experiencing a climatic warming and drying trend [12]. Severe groundwater exploitation has accelerated the shortage of water resources [13]. Since the 1990 s the flow of the Yellow River has decreased by up to $65 \%$ compared with the average value of the $1950 \mathrm{~s}-90 \mathrm{~s}$, and one of the hydrological stations along the Yellow River, Lijin Station, observed zero flow for 226 days in 1997 [14]. In order to conserve water and soil and actively improve the ecological environment, China has made the Loess Plateau a key pilot area of the "Three North" Protection Forest Project and launched a large-scale tree planting and forestation movement in 1978. Luoyugou, a typical watershed in the Loess Plateau, is very vulnerable to climate change and can be strongly affected by human activity. It becomes more and more important to assess the impact of climate variation and human activity on runoff to provide a scientific basis for ecological restoration and developing sustainable catchment management strategies.

The purpose of this paper is to separate the effects of land use change and climate change on the rainfall runoff process in a small Loess catchment. Specifically, the following issues will be addressed:

- Determine the trends and change points in annual runoff, precipitation, and evapotranspiration.

- Analyze the trend of land use change.

- Estimate the impacts of climate change and human activity on runoff and figure out their respective contribution rates.

\section{Materials and Methods}

\section{Study Area}

The study was conducted in Luoyugou in the third sub-region of the Loess Plateau, Gansu Province, in northwestern China. This site is located at latitude $34^{\circ} 36^{\prime} 13^{\prime \prime} \mathrm{N}, 34^{\circ} 39^{\prime} 7^{\prime \prime} \mathrm{N}$ and longitude between $105^{\circ} 30^{\prime} 11^{\prime \prime} \mathrm{E}$ and $105^{\circ} 43^{\prime} 8^{\prime \prime} \mathrm{E}$, and ranges 1,200-1,895 $\mathrm{m}$ in elevation. The entire basin covers an area of 72.79 $\mathrm{km}^{2}$ with a main channel length of $21.63 \mathrm{~km}$ and channel gradient of $2.3 \%$, and gully density of $3.54 \mathrm{~km} / \mathrm{km}^{2}$. The climate in the study area presents the characteristic of transition zone of sub-humid to semiarid. Average annual precipitation is $548.9 \mathrm{~mm}$, with approximately $60 \%$ of the precipitation occurring from June to September. Mean annual temperature, mean maximum temperature of the hottest month, and mean minimal temperature of the coldest month are $10.7^{\circ} \mathrm{C}, 22.6^{\circ} \mathrm{C}$, and $-2.3^{\circ} \mathrm{C}$, respectively. The average annual pan evaporation is about $1,293.3 \mathrm{~mm}$. The soil of the study site is classified into 11 types. Among those complex types, $91.7 \%$ of the total soil belongs to hilly gray cinnamonic soil. The arbor in the watershed belongs to artificial vegetation, including Salix matsudana, Ulmus pumila, Robinia pseudoacacia, Pinus tabulaeformis, and Platycladus orientalis. In addition, the main natural shrubs are Sophora viciifolia, Amorpha fruticose, and Zanthoxyhum bungeanum, etc.

Eleven rainfall station and one national weather station are located in or around the watershed, and a hydrological station is equipped as the control station for the whole watershed.

\section{Databases}

We developed a GIS database to study the structure, spatial patterns, and evolution of the landscape in the Luoyugou watershed. Four resolution data sets were generated from four aerial photographs of 1993, 2002, 2008, and 2015 in the study area. The aerial photographs of 1993 and 2002 are landsat TM while the 2008 and 2015 images are $\mathrm{ETM}^{+}$and spot, respectively. All the thematic maps were of $10 \mathrm{~m}$ accuracy and stored in 
GIS using ARC/INFO and ERDAS software on UNIX workstations and PCs. All the layers were stored in vector format, where information is defined by points, lines, or polygons.

Annual runoff data was available for the period of 1986-2015 from the control station. Annual precipitation from 1960 to 2015 was observed from the 11 rainfall stations in Luoyugou. Potential evapotranspiration was calculated with day-to-day minimum and maximum air temperatures, relative humidity, hours of sunshine, and wind speed for the period of 1960-2015 from 11 national weather stations, using the Penman-Monteith equation recommended by FAO [15].

\section{Statistical Methods}

Mann-Kendall test was employed to detect trends of runoff, precipitation, and potential evapotranspiration series over the observation period. It was first adopted by Hirsch et al. from Mann-Kendall's test and was later used by Gan to analyze the hydroclimatic trends in Canadian prairies [16-18]. This test was used as the analytical tool of choice because the model works for the non-normalities in unusual data reports; and the model has high asymptotic efficiency [19]. In addition, moving t-test and hopped parameter were used to validate the Mann-Kendall test.

To predict stream flow under changing climatic conditions, a rational ET model proposed by Zhang et al. was used [20], which was established on the basis of data observation from more than 300 small watersheds across a large climatic gradient around the world. Zhang's model has closely related ET to $P$ and $P E T$. Thus, combined with a water budget equation $(Q=P$-ET $)$, runoff variation can be determined under the changed climate conditions given specific land surface characteristics.

Mann-Kendall test has been used for trend detection in hydrological and meteorological variables [21]. A data series was composed of $x_{1}, x_{2}, \ldots, x_{n}$ for each element and $r_{i}$ as the number of later terms in the series for which values exceeding $\mathrm{x}_{\mathrm{i}}$ are to be computed. Under the null hypothesis of no trend, the rank statistic $S_{k}$ is given by

$$
s_{k}=\sum_{i=1}^{k} r_{i}, \mathrm{k}=2,3 \ldots \mathrm{n}
$$

Where

$$
r_{i}=\left\{\begin{array}{l}
+1, \text { when } x_{i}>x_{j}, \\
0, \text { when } x_{i} \leq x_{j}, \quad \mathrm{j}=1,2 \ldots \mathrm{i}
\end{array}\right.
$$

$$
\mathrm{UF}_{\mathrm{k}}=\frac{\left[S_{k}-E\left(S_{k}\right)\right]}{\sqrt{\operatorname{var}\left(S_{k}\right)}}, \quad \mathrm{k}=1,2 \ldots \mathrm{n}
$$

In the formula, $U F_{1}=0, E\left(s_{k}\right)$, and var $\left(S_{k}\right)$ are the mean and variance of $S_{k}$. It is normally distributed with mean and variance given by

$$
\left\{\begin{array}{l}
E\left(s_{k}\right)=\frac{n(n+1)}{4} \\
\operatorname{var}\left(s_{k}\right)=\frac{n(n-1)(2 n+5)}{72}
\end{array}\right.
$$

$U F_{i}$ was a statistic series presenting standardized normal distribution, which was calculated by a data series composed of $x_{1}, x_{2}, \ldots, x_{n}$. Given a significance level of $a$ and normal distribution checked table, the null hypothesis of no trend will be rejected at a significance level of $a$ if the standard normal probability $\left|U F_{i}\right|>|U a|$. The graphical representation of the collection of all $U F_{i}(1<k<n)$ is denoted by $C_{l}$. The method is then used to invert the series in order to obtain a new data series called $C_{2}$. The intersection point of $C_{1}$ and $C_{2}$, located between the confidence lines, is the time of abrupt change. The trend of series presents upward if $C_{1}$ and $C_{2}$ exceed zero; in contrast, the series shows itself as a downtrend.

The method was used to test differences between averages of two groups of random samples. The n-sample series to be analyzed was divided into two subsets where $\bar{x}_{i}, S_{i}^{2}$, and $n_{i}$ represent the average, variance, and length of the sample. The statistic is defined as:

$$
t=\frac{\bar{x}_{1}-\bar{x}_{2}}{\sqrt{\frac{n_{1} s_{1}^{2}+n_{2} s_{2}^{2}}{n_{1}+n_{2}-2}\left(\frac{1}{n_{1}}+\frac{1}{n_{2}}\right)}}
$$

Given significance level $a$, the null hypothesis of no difference will be rejected if $|t|>t_{a / 2}$. The maximum $|t|$ indicates that an abrupt change may appear. $n_{1}=n_{2}=5$ and $n_{1}=n_{2}=10$ were used in this study for different lengths of subsequent sets and may lead to inconsistent results. Details of this method can be found in [22].

The hopped parameter $J_{y}$ was used to validate MannKendall test and Moving t-test. $J_{y}$ is noted as follows:

$$
J_{y}=\left|M_{1}-M_{2}\right|\left(S_{1}+S_{2}\right)
$$

...where subscript y represents the moment of the series of climatic factor, $M_{1}$ and $M_{2}$ are mean values of $\mathrm{N}$ years before and after $y$, and $S_{1}$ and $S_{2}$ are mean square deviation of $\mathrm{N}$ years before and after $y$. When $J y>1$, it indicates the series hopped around $y$ year; when $J y>2$, the jump is dramatically around $y$ year [23].

In order to estimate the impact of climate change and LUCC change on runoff, annual mean runoff change $\Delta Q^{\text {tot }}$ was regarded as combinatorial runoff change reduced by climate change $\Delta \bar{Q}^{\text {clim }}$ and LUCC change $\Delta \bar{Q}^{\text {LUCC }}$ [24]. Runoff change is noted as follows:

$$
\Delta Q^{\mathrm{tot}}=\Delta \bar{Q}^{\mathrm{clim}}+\Delta \bar{Q}^{\mathrm{LUCC}}
$$


In the formula, $\Delta Q^{\text {tot }}$ represents the difference of annual mean runoff between two periods at abrupt change points. It is noted as follows:

$$
\Delta Q^{\mathrm{tot}}=\Delta \bar{Q}_{2}-\Delta \bar{Q}_{1}
$$

$\Delta \bar{Q}_{2}$ is the annual average runoff after change. $\Delta \bar{Q}_{1}$ is the annual average runoff before change.

Given that land use has no change, $\Delta \bar{Q}^{\text {clim }}$ is the annual average runoff change which is reduced by climatic variation $[10]$
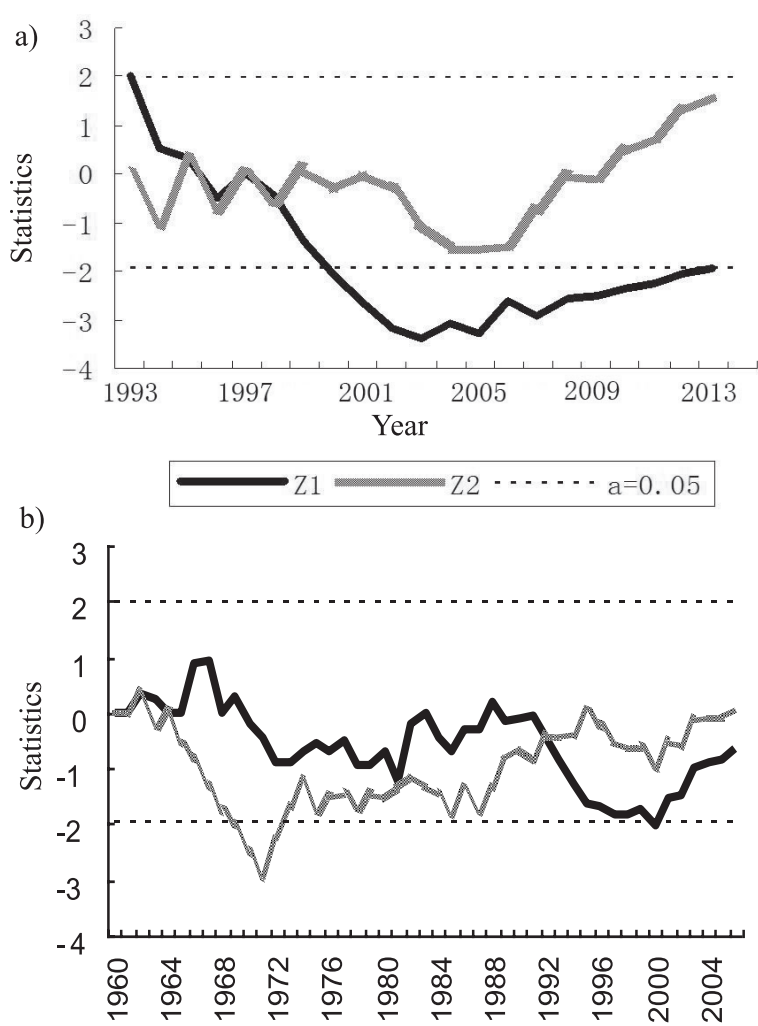

c)

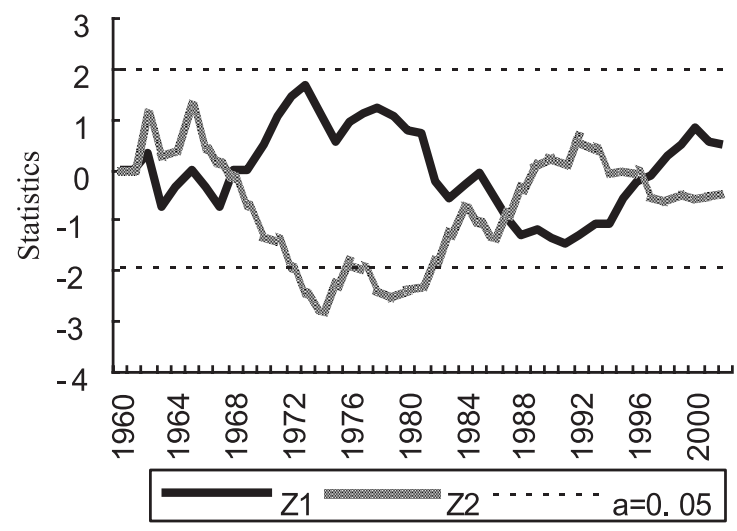

Fig. 1. Mann-Kendall test of annual runoff a), precipitation b), and potential evapotranspiration c).

$$
\Delta \bar{Q}^{\mathrm{clim}}=\beta \Delta P+\gamma \Delta E_{0}
$$

...where $\Delta P$ and $\Delta E_{0}$ are changes in rainfall and potential evapotranspiration and $\beta$ and $\gamma$ are the runoff sensitivity coefficients of $P$ and $E_{0}$. When Zhang's function was used, these can be expressed as follows:

$$
\begin{gathered}
E=\left[\frac{1+w \frac{E_{0}}{P}}{1+w \frac{E_{0}}{P}+\frac{P}{E_{0}}}\right] \times P \\
\beta=\frac{1+2 \mathrm{x}+3 \mathrm{wx}^{2}}{\left(1+\mathrm{x}+\mathrm{wx}^{2}\right)^{2}}
\end{gathered}
$$

$$
\gamma=-\frac{1+2 w x}{\left(1+x+w^{2}\right)^{2}}
$$

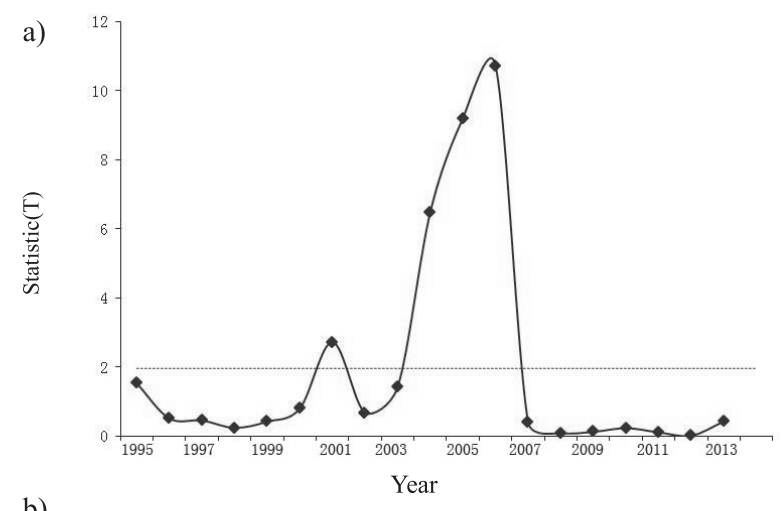

b)
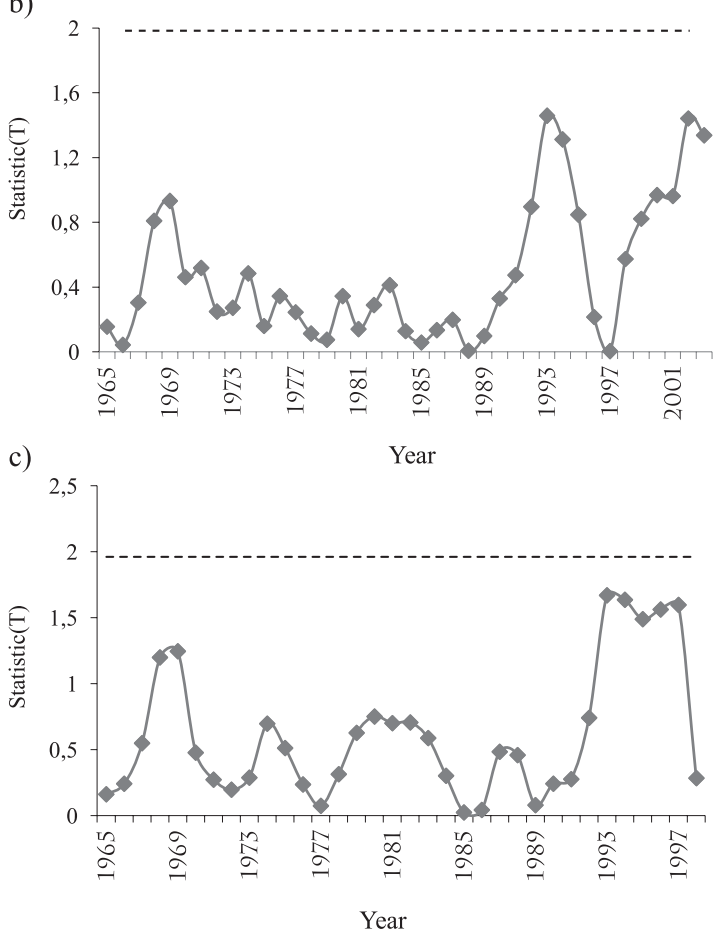

Fig. 2. Moving t-test of annual runoff a), precipitation b), and potential evapotranspiration c). 


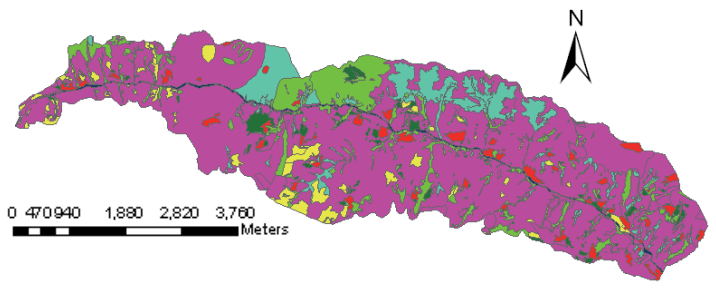

a) 1993

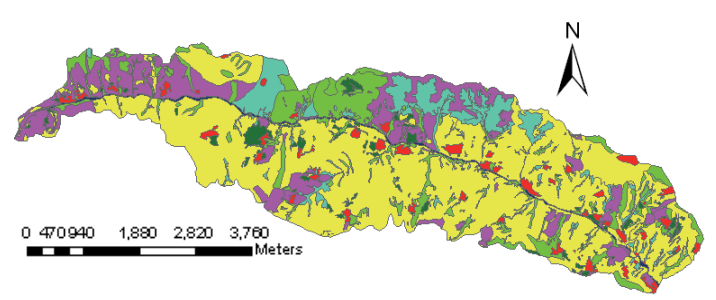

c) 2008

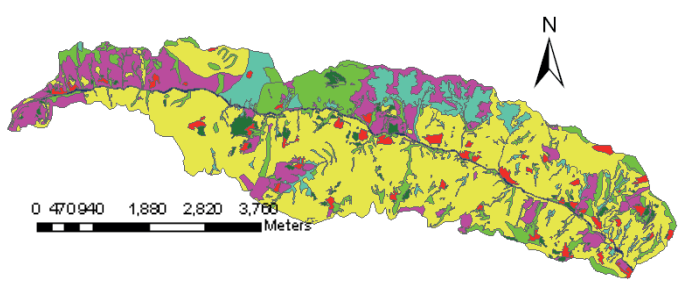

b) 2002

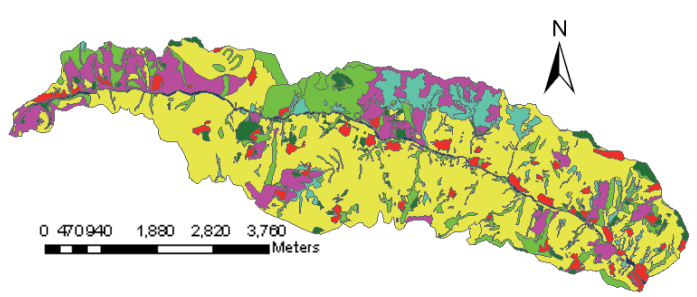

d) 2015

\section{Legend}

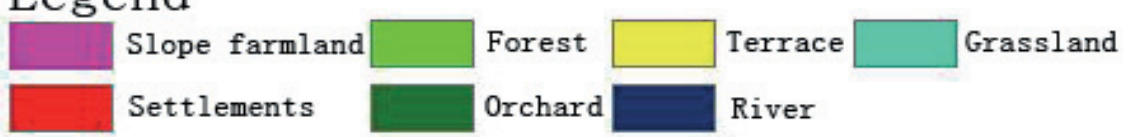

Fig. 3. Different period land use construction of Luoyugou watershed.

...where $x\left(x=E_{0} / P\right)$ is drought index and $\mathrm{w}$ is an integrative parameter related to the underlying surface [25]. As terrain and soil have changed little in 23 years, w is mainly affected by vegetation and is calculated by $w_{i}$ weighting area of different land types.

\section{Results and Discussion}

\section{Changes of Runoff, Climate, and Land Use}

To analyze the trend and change point of runoff, precipitation, and potential evapotranspiration data series in the Luoyugou watershed, the nonparametric MannKendall test and moving t-test were used. As shown in Fig. 1a), the annual runoff presented obvious decreasing tendency and exceeded the significance level of $5 \%$. The change point of annual runoff occurred in 1999 at a 5\% significance level. A result was found by the moving t-test in Fig. 2a), when both $n_{1}$ and $n_{2}$ were 5, suggesting the robustness of the detected abrupt change in 2001. And combined with hopped parameter $J_{v}$, it reached 1.96 and presented strongly hopped change in 2001. Given this result, the period of the annual runoff could be divided into two parts: a baseline period (1993-2001) and a period of change (2002-15).

Annual precipitation decreased slightly at a 5\% significance level, so it had no significant change. And the change point of annual precipitation was presented in 2000 at a $5 \%$ significance level (Fig. 1b). However, the change point of the sequence series of precipitation was not found in Fig. 2b) by moving t-test. Through the hopped parameter $J_{v}$ an abrupt change in 2000 was found $\left(J_{y}=1.12\right)$. The annual potential evapotranspiration fluctuated up and down at a 5\% significance level and had no significant change, and two change points that occurred between 1995 and 2003 at a 5\% significance level (Fig. 1c). However, the change point of the sequence series of potential evapotranspiration was not found in Fig. 2c) by moving t-test. According to hopped parameter $J_{y}$, the $J_{v}$ (from 2000 to 2004) was greater than 1 , which indicated the series hopped around those years. The maxim of $J_{v}$ was 1.18 , presenting in 2000 .

From four remote sensors in different periods, land use structure was observed. The study region covered a total area of $72.79 \mathrm{~km}^{2}$. Among the seven land use types, slope farmland and terrace were the most converted types during the entire study period. From 1993 to 2015, the trend of slope farmland decreased gradually; in contrast, the terrace was increased (Fig. 3). As shown in Table 1, in the total study area $\left(72.79 \mathrm{~km}^{2}\right)$ an orchard constituted $2.84 \%, 2.98 \%, 2.99 \%$, and $5.87 \%$ in the years 1993,2002 , 2008, and 2015, respectively. In 1993 the area covered by forest was $7.89 \mathrm{~km}^{2}$ (10.84\% of the study area), which increased to $9.97 \mathrm{~km}^{2}(13.7 \%)$ in 2002 and $10.06 \mathrm{~km}^{2}$ $(13.82 \%)$ in 2008 , and $10.13 \mathrm{~km}^{2}(13.92 \%)$ in 2015 . The area under grassland (i.e., the majority land cover type) was about $6.76 \mathrm{~km}^{2}(9.29 \%)$ in 1993 , but it was cut down 
Table 1. Area and percentage of land use types in Luoyugou watershed $\left(\mathrm{km}^{2}\right)$.

\begin{tabular}{|c|c|c|c|c|c|c|c|c|}
\hline \multirow{2}{*}{ Land type } & \multicolumn{3}{|c|}{1993} & \multicolumn{2}{c|}{2002} & \multicolumn{2}{c|}{2008} & \multicolumn{2}{c|}{2015} \\
\cline { 2 - 10 } & Area & Percentage & Area & Percentage & Area & Percentage & Area & Percentage \\
\hline Slope farmland & 49.23 & 67.63 & 11.23 & 15.43 & 11.18 & 15.36 & 9.49 & 13.04 \\
\hline Terrace & 3.09 & 4.25 & 39.05 & 53.65 & 39.03 & 53.62 & 39.76 & 54.62 \\
\hline Forest & 7.89 & 10.84 & 9.97 & 13.70 & 10.06 & 13.82 & 10.13 & 13.92 \\
\hline Grassland & 6.76 & 9.29 & 6.63 & 9.11 & 6.59 & 9.05 & 5.05 & 6.94 \\
\hline Orchard & 2.07 & 2.84 & 2.17 & 2.98 & 2.18 & 2.99 & 4.27 & 5.87 \\
\hline River & 1.06 & 1.46 & 1.06 & 1.46 & 1.06 & 1.46 & 0.84 & 1.15 \\
\hline Settlements & 2.69 & 3.70 & 2.69 & 3.70 & 2.69 & 3.70 & 3.25 & 4.46 \\
\hline Total & 72.79 & 100.00 & 72.79 & 100.00 & 72.79 & 100.00 & 72.79 & 100.00 \\
\hline
\end{tabular}

to $6.63 \mathrm{~km}^{2}(9.11 \%)$ in 2002 and to $6.59 \mathrm{~km}^{2}(9.05 \%)$ in 2008 (Table 2). From 2008 to 2015, it decreased greatly, by about $6.94 \%$. During the entire period, the river did not show a significant change $(0.31 \%$ decrease). It kept steady from 1993 to 2015 while decreasing to $1.15 \%$ in 2015. The proportion of settlements also remained unchanged. The area under this category was $2.69 \mathrm{~km}^{2}$ in the periods under study (1993-2008); from 2008 to 2015 , the settlements increase from $2.69 \mathrm{~km}^{2}(3.70 \%)$ to $3.25 \mathrm{~km}^{2}(4.46 \%)$ (Table 1).

\section{Sensitivity of Runoff to Changes in $P$ and $P E T$}

The term $\beta$ and $\gamma$ in Eqs. (10) and (11) can be considered the sensitivity coefficients of runoff to changes in precipitation and potential evapotranspiration, respectively. The relationship between the sensitivity coefficients and the dryness index $\left(E_{0} / P\right)$ with different $w$ value is shown in Figure 4.

As in Li's study, the sensitivity coefficient $\beta$ to precipitation is higher for lower $w$ values and decreases with the dryness index. The relationships indicate that a change in precipitation will lead to a greater change in runoff in grassed catchments than in forested catchments, as forested catchments generally have larger $w$ values. The sensitivity coefficient $\gamma$ to potential evapotranspiration is higher for larger $w$ values when the dryness index is less than 2.6 (Fig. 4). The drought index was about 1.1-2.6 under our study in the small area. The changes of $\beta$ and $\gamma$ sensitivity coefficient could not be calculated with the changes of $w$ and drought index when drought index was greater than 2.6 or less than 1.1. The relationships suggest that catchments in humid regions would respond more strongly to changes in precipitation and potential evapotranspiration than catchments in arid regions.
However, the magnitude of the changes in runoff depend on both the sensitivity coefficients and changes in rainfall and potential evapotranspiration.

\section{Effects of Climate Variability and Human Activity on Runoff}

Runoff is a result of catchment processes and is affected by many factors, and it is widely recognized that runoff changes are influenced by both climate variability and human activity [26-27]. Changes in any of the factors such as climate and land use/cover may result in changes in runoff. However, quantification of the individual impact is difficult as most changes in runoff are associated with changes in both climate and human activity. The impact of climate variability on runoff was estimated using the method described in the previous section. The series of runoff was divided into two parts according to the trend of runoff change: a baseline period (1993-2001) representing runoff under natural conditions and a period of change (2002-15), representing runoff under the impact of climate change and human activity.

The $w$ represents model parameters in Zhang's function (in Equation 9). The $\mathrm{w}$ in Zhang's function is plant-available water coefficient, representing the relative difference in the way plants use soil water for transpiration, and believed to be mainly owing to differences in root zone depth $[20,28]$. Under certain circumstances, when soil properties and topography were similar, forests generally have the largest $\mathrm{w}$ values, followed by short grass and crops, while bare land has the smallest value.

Based on Equations (6-8), the effects of climate change and land use changes on runoff were calculated where model parameter $\mathrm{w}$ was calculated according to land-use data in 1993. From Table 2, results calculated by Zhang's function showed that climate change accounted

Table 2. Contribution rates of runoff on climate and land-use changes.

\begin{tabular}{|c|c|c|c|c|c|c|}
\hline Period & $P(\mathrm{~mm})$ & $E_{0}(\mathrm{~mm})$ & $Q(\mathrm{~mm})$ & $\Delta Q^{\text {tot }}(\mathrm{mm})$ & $\Delta \bar{Q}^{\text {clim }}(\%)$ & $\Delta \bar{Q}^{\text {LUCC }}(\%)$ \\
\cline { 1 - 3 } $1993-2001$ & 541.1 & $1,032.72$ & 35.14 & \multirow{2}{*}{15.14} & 33.10 & 66.90 \\
\cline { 1 - 4 } $2002-15$ & 606.05 & $1,073.15$ & 20.10 & & \\
\hline
\end{tabular}



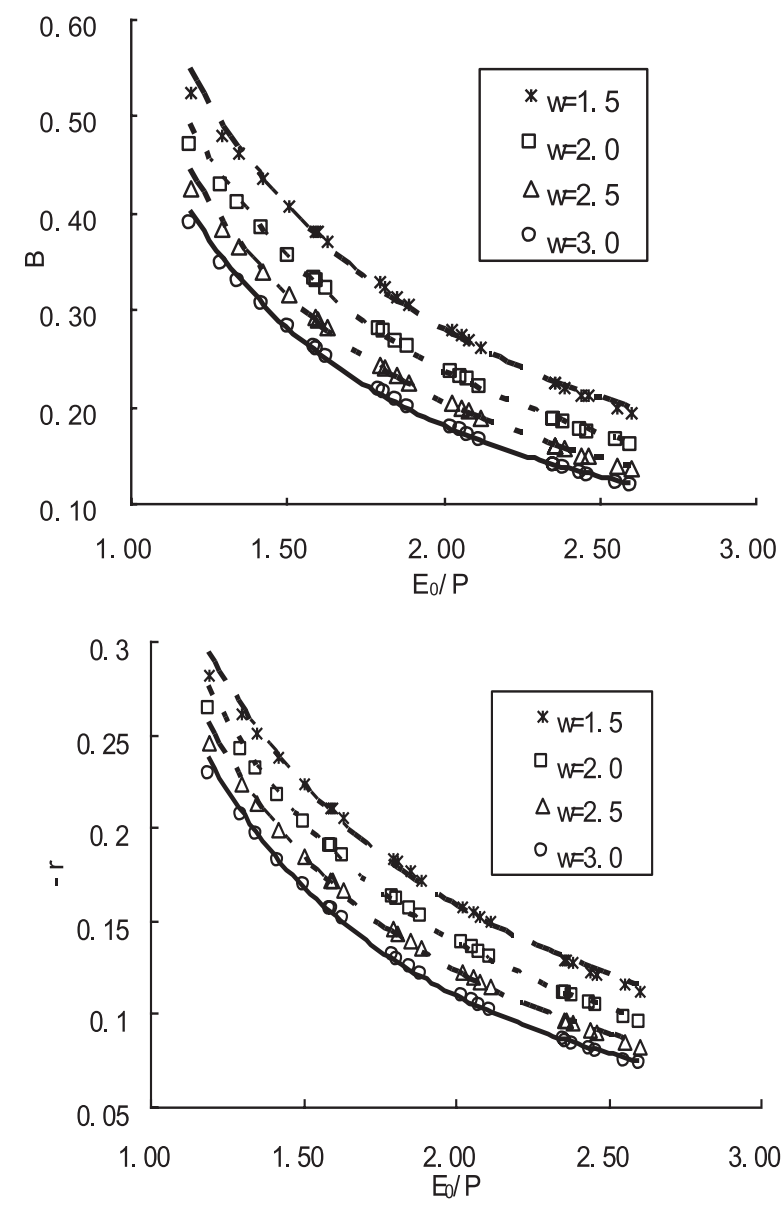

Fig. 4. Relationship between $\beta, \gamma$ sensitivity coefficient, and drought index.

for $33.1 \%$ of the observed change in mean annual runoff and human activity for $66.9 \%$.

\section{Conclusions}

In conclusion, a significant downtrend has been found in annual runoff in the Luoyugou watershed. The main aim of this paper was to analyze the decrement in mean annual runoff induced by climate change and human activity. The decrease in mean annual runoff between the baseline and the period of change indicated that climate change accounted for about $33.1 \%$ of the total decrease, and human activity was responsible for about $66.9 \%$. Climate change was mainly the decrease of precipitation and increase of potential evapotranspiration, and human activity was mainly the land use changes, which were the transformation of slope farmland to terrace and the increasing of forest and orchard land.

\section{Acknowledgements}

This study was financially supported by the National key research priorities program of China
(2016YFC0402402), the National Natural Sciences foundation of China (41601301, 41571276). and Science and technology development fund of the Yellow River Institute of Hydraulic Research(HKF201707).

\section{References}

1. CHEN J., BRISSETTE F.P., LUCAS P. Transferability of optimally-selected climate models in the quantification of climate change impacts on hydrology. Climate Dynamics. 22, 1, 2016.

2. SELLAMI H., BENABDALLAH S., JEUNESSE I.L. Climate models and hydrologic parameter uncertainties in climate change impacts on monthly runoff and daily flow duration curve of a Mediterranean catchment. Hydrological Sciences Journal. 8, 61, 2015.

3. QIU L., ZHENG F., YIN R. Quantification of Impacts of Precipitation Change and Human Activity on Streamflow in the Yanhe River Basin. Advances in Climate Change Research. 7, 357, 2011.

4. ZHAO G., TIAN P., MU X. Quantifying the impact of climate variability and human activity on streamflow in the middle reaches of the Yellow River basin, China. Journal of Hydrology. 519, 387, 2014.

5. PROKOPY L.S., MORTON L.W., ARBUCKLE J.G. Agricultural Stakeholder Views on Climate Change: Implications for Conducting Research and Outreach. Bulletin of the American Meteorological Society. 96, 2, 2015.

6. WANG F., HESSEL R., MU X. Distinguishing the impacts of human activity and climate variability on runoff and sediment load change based on paired periods with similar weather conditions: A case in the Yan River, China. Journal of Hydrology, 527, 884, 2015.

7. ZHANG J., LIN X., GUO B. Multivariate Copula-Based Joint Probability Distribution of Water Supply and Demand in Irrigation District. Water Resources Management. 30, 23612016.

8. SHI P.J., GONG P., LI X.B. Methods and Practice of Land Use and Land cover change, Beijing: Science Press, 2016.

9. CHEN J.F., CHEN X.W. Water balance of SWAT model and its application in the Suomo Basin. Acta Sci Nat Uni Pelin 40, 265, 2016.

10. SELLAMI H., BENABDALLAH S., LA J.I. Quantifying hydrological responses of small Mediterranean catchments under climate change projections. Science of the Total Environment. 543, 924, 2015.

11. LI L.J., LI B., LIANG L.Q. Effect of climate change and land use on stream flow in the upper and middle reaches of the Taoriver, northeastern China. For Stud China 12, 107, 2015.

12. LIU X.Q., ZHAO J.B., YU F. Study on the Climatic Warming Drying Trend in the Loess Plateau and the Countermeasures. Arid Zone Research 23, 627, 2016.

13. WANG S.P., ZHANG Z.Q., SUN G. Long-term streamflow response to climatic variability in the Loess Plateau, China. Journal of the American Water Resources Association 44, 1098, 2008.

14. LIU C.M., Zhang X.C. Analysis on Actual Water Flow Reduction in the Mainstream of the Yellow River. Acta Geographica Sinica 59, 323, 2014.

15. REFSGAAED J.C., MADSEN H. A framework for testing the ability of models to project climate change and its impacts. Climatic Change. 122, 271, 2014. 
16. LANDES A.L., AQUILINA L., RIDDER J.D. Investigating the respective impacts of groundwater exploitation and climate change on wetland extension over 150 years. Journal of Hydrology. 509, 367, 2014.

17. WANG Z.G., LUO Y.Z., ZHU X.J. Watershed modeling of surface water-groundwater interaction under projected climate change and water management in the Haihe River Basin, China. British Journal of Environment \& Climate Change. 3, 421, 2013.

18. TAN M.L., IBRAHIM A.L., YUSOP Z. Impacts of landuse and climate variability on hydrological components in the Johor River basin, Malaysia. Hydrological Sciences Journal. 60, 873, 2015.

19. ZHANG L., NAN Z., XU Y. Hydrological Impacts of Land Use Change and Climate Variability in the Headwater Region of the Heihe River Basin, Northwest China. Plos One. 11, 6, 2016.

20. PORTMANN F.T., DOLL P., EISNER S. Impact of climate change on renewable groundwater resources: assessing the benefits of avoided greenhouse gas emissions using selected CMIP5 climate projections. Environmental Research Letters. 8, 23, 2013.

21. HUANG S., HUANG Q., CHEN Y. Quantitative estimation on contributions of climate changes and human activity to decreasing runoff in Weihe River Basin, China. Chinese Geographical Science. 25, 569, 2015.
22. DONG L.Q., ZHANG G.X., XU Y.J. Effects of climate change and human activity on runoff in the Nenjiang River Basin, Northeast China. Hydrology \& Earth System Sciences Discussions. 9, 11521, 2012.

23. CHANG J., WANG Y., ISTANBULLUOGLU E. Impact of climate change and human activity on runoff in the Weihe River Basin, China. Quaternary International. 380, 2015.

24. GLENN E.P., NAGLER P.L., HUETE A.R. Vegetation Index Methods for Estimating Evapotranspiration by Remote Sensing. Surveys in Geophysics 31, 531, 2010.

25. LI L.J., ZHANG L., WANG H. Assessing the impacts of climate variability and human activity on stream flow from Wuding river basin in China. Hydro Process 21, 3485, 2007.

26. PIAO S.L., FRIEDLINGSTEIN P., CIAIS P., NOBLETDUCOUDRE N., LABABT D., ZAEHLE S. Changes in the climate and land use have a larger direct impact than rising $\mathrm{CO}_{2}$ on global river flows. Proc. Natl. Acad. Sci. U.S.A. 104, $15242,2007$.

27. WANG H., CHEN L., YU X. Distinguishing human and climate influences on streamflow changes in Luan River basin in China. Catena. 136, 182, 2016.

28. TABARI H. Evaluation of Reference Crop Evapotranspiration Equations in Various Climates. Water Resources Management 24, 2311. 2010. 